\title{
The equation of state and high-pressure behavior of magnesite
}

\author{
NANCY L. Ross \\ Research School of Geological and Geophysical Sciences, University College London, Gower Street, London WC1E 6BT, U.K.
}

\begin{abstract}
Unit-cell parameters of magnesite have been measured to high precision between 0 and $7 \mathrm{GPa}$ using single-crystal X-ray diffraction. The isothermal bulk modulus of magnesite determined from fitting a Birch-Murnaghan third-order equation of state to the volume compression data is $K_{T}=117(3) \mathrm{GPa}$ with $K_{T}^{\prime}=2.3(7)$, and $K_{T}=111(1) \mathrm{GPa}$ if $K_{T}^{\prime}$ is constrained to a value of 4 . Crystal structure parameters have been determined from X-ray intensity data at room pressure, 2.26, 3.09, 4.16, 4.77, and $6.05 \mathrm{GPa}$. The principal structural change with increasing pressure is compression of the $\mathrm{MgO}_{6}$ octahedra while the $\mathrm{CO}_{3}$ group remains invariant (within the experimental uncertainty) throughout the pressure range studied. The effect of the polyhedral compression is reflected in the anisotropic compression of the unit-cell parameters with the $c$ axis approximately twice as compressible as the $a$ axis. The polyhedral bulk modulus of the $\mathrm{MgO}_{6}$ octahedron is $113 \mathrm{GPa}$, which is greater than that observed in other rhombohedral carbonates, but significantly smaller than values observed in many oxides and silicates. The distortion of the octahedra, though already small, decreases slightly with pressure. No phase change or change in compression behavior was observed throughout the pressure range studied.
\end{abstract}

\section{INTRODUCTION}

There has been considerable interest in the stabilities of carbonates at high pressures and temperatures, especially since experimental studies and the observed occurrence of carbonates in mantle-derived samples have indicated that carbonates could be hosts for C in the Earth's mantle (McGetchin and Besançon 1973; Kushiro et al. 1975; Wyllie and Huang 1976; Berg 1986; Canil and Scarfe 1990; Biellman et al. 1993). Among the carbonates, it has been shown that magnesite is stable in peridotite compositions at high pressures and temperatures (Brey et al. 1983; Katsura and Ito 1990; Biellman et al. 1993). Martinez et al. (1996) observed that dolomite breaks down to aragonite plus magnesite at $7 \mathrm{GPa}$ and $973 \mathrm{~K}$. All of this evidence suggests that magnesite should be considered when evaluating the role of $\mathrm{C}$ in the mantle.

Redfern et al. (1993) determined the isothermal bulk modulus $\left(K_{T}\right)$ of magnesite from pressure-volume data collected between 0 and $20 \mathrm{GPa}$ and calculated the stability field of magnesite combining their results with other thermodynamic data. They concluded that magnesite is stable in the presence of $\mathrm{MgO}$ under pressure-temperature conditions of the lower mantle. Fiquet et al. (1994) also determined the bulk modulus of magnesite from pressure-volume data collected between 0 and $53 \mathrm{GPa}$. At $25 \mathrm{GPa}$, they observed anomalies in the compression curve and new diffraction peaks, and suggested that magnesite undergoes a phase transition. Gillet (1993), however, studied the stability of magnesite using Raman spectroscopy to $32 \mathrm{GPa}$ and found that magnesite does not undergo any phase transition under quasihydrostatic con- ditions, in agreement with high-pressure experiments of Williams et al. (1992) and Katsura et al. (1991). Gillet (1993) also showed that magnesite retains its $\mathrm{R}^{\overline{3}} \mathrm{c}$ structure at simultaneous high pressure $(26 \mathrm{GPa})$ and high temperature $(1200 \pm 200 \mathrm{~K})$. Recently, Zhang et al. (1996) carried out in situ X-ray diffraction studies on magnesite at high pressure and temperature using a DIAtype cubic-anvil apparatus, interfaced with synchrotron powder diffraction. They measured the molar volume of magnesite up to $9 \mathrm{GPa}$ and $1300 \mathrm{~K}$, and derived equationof-state parameters, including the pressure and temperature derivatives of $K_{T}$.

The isothermal bulk moduli determined by the three highpressure X-ray diffraction studies show some disagreement. Both Redfern et al. (1993) and Fiquet et al. (1994) determined the isothermal bulk modulus of magnesite using powder X-ray diffraction with a synchrotron radiation source and collecting data from a diamond-anvil cell in an energydispersive mode at room temperature. Using the Birch equation of state with $K_{T}^{\prime}$ constrained to be 4 , Redfern et al. (1993) obtained $K_{T}=142(9) \mathrm{GPa}$ and Fiquet et al. (1994) obtained $K_{T}=138(3) \mathrm{GPa}$. When $K_{T}^{\prime}$ is not constrained, Redfern et al. (1993) found that a full Birch-Murnaghan equation of state yields $K_{T}=151(7) \mathrm{GPa}$ and $K_{T}^{\prime}=2.5$. Fiquet et al. (1994) found similar values with $K_{T}=156(4)$ GPa and $K_{T}^{\prime}=2.5(2)$. Zhang et al. (1996) derived equationof-state parameters from a third-order Birch-Murnaghan equation of state that are much lower than the earlier studies, $K_{T}=108(3)$ and $K_{T}^{\prime}=2.3$, and $K_{T}=103(1) \mathrm{GPa}$ when $K_{T}^{\prime}=4$. These values, however, are in good agreement with adiabatic bulk moduli $\left(K_{S}\right)$ determined from acoustic mea- 
TABLE 1. Unit-cell parameters of magnesite to $6.88 \mathrm{GPa}$

\begin{tabular}{cclc}
\hline \hline$P(\mathrm{GPa})$ & $a(\AA)$ & $c(\AA)$ & $V\left(\AA^{3}\right)$ \\
\hline 0.00 & $4.6339(4)$ & $15.0177(9)$ & $279.28(3)$ \\
0.30 & $4.6331(4)$ & $15.0016(10)$ & $278.87(5)$ \\
0.74 & $4.6282(4)$ & $14.9717(6)$ & $277.73(3)$ \\
1.39 & $4.6216(5)$ & $14.9268(9)$ & $276.14(6)$ \\
1.75 & $4.6192(6)$ & $14.900(1)$ & $275.32(7)$ \\
1.93 & $4.6162(3)$ & $14.8882(7)$ & $274.75(4)$ \\
2.26 & $4.6149(4)$ & $14.867(1)$ & $274.20(5)$ \\
2.34 & $4.6126(3)$ & $14.8652(6)$ & $273.90(3)$ \\
2.71 & $4.6101(5)$ & $14.837(1)$ & $273.08(6)$ \\
3.09 & $4.6068(4)$ & $14.8170(9)$ & $272.33(4)$ \\
3.34 & $4.6044(4)$ & $14.7973(9)$ & $271.68(5)$ \\
3.70 & $4.6009(3)$ & $14.7751(6)$ & $270.86(3)$ \\
4.02 & $4.5995(6)$ & $14.751(1)$ & $270.26(7)$ \\
4.16 & $4.5988(4)$ & $14.7525(9)$ & $270.20(5)$ \\
4.77 & $4.5937(4)$ & $14.7157(11)$ & $268.93(5)$ \\
5.61 & $4.5850(2)$ & $14.6588(5)$ & $266.87(3)$ \\
6.05 & $4.5812(3)$ & $14.6302(6)$ & $265.91(3)$ \\
6.42 & $4.5788(2)$ & $14.6128(5)$ & $265.32(2)$ \\
6.88 & $4.5747(2)$ & $14.5826(4)$ & $264.30(2)$ \\
\hline
\end{tabular}

Note: Standard deviations ( 1 esd) in parentheses.

surements by Christensen (1972) and Humbert and Plicque (1972) who reported values of $112 \mathrm{GPa}$ and $113.8 \mathrm{GPa}$, respectively.

In this study, high-precision unit-cell volume measurements of magnesite measured between 0 and $7 \mathrm{GPa}$ are reported. Isothermal bulk moduli obtained from a thirdorder Birch-Murnaghan equation of state are compared with the previous determinations of $K_{T}$, and the role of nonhydrostatic pressure media is discussed. In addition, the structural changes of magnesite with pressure are described and compared with more Ca-rich carbonates with similar structures.

\section{EXPERIMENTAL DETAILS}

The magnesite crystal used in this study was taken from a clear cleavage rhomb kindly provided by the British Museum of Natural History (BM 1984,547). A crystal measuring $80 \times 65 \times 30 \mu \mathrm{m}$ was selected after examination with the polarizing microscope that showed that the crystal was clear, free of inclusions, and appeared to be a single crystal. Further examination on the diffractometer verified that the crystal was untwinned and had sharp, well-defined diffraction peak profiles. The crystal was mounted in a DXR4 type diamond-anvil cell (Angel et al. 1992) with an Inconel $750 \times$ gasket $(250 \mu \mathrm{m}$ diameter hole). The crystal and a $15 \mu \mathrm{m}$ chip of ruby pressure calibrant were affixed to one diamond face with a thin smear of the alcohol-insoluble fraction of vaseline, and a 4:1 mixture of non-dried methanol:ethanol was the hydrostatic pressure-transmitting medium. The pressure was calculated by measuring the shift of the $R_{1}$ fluorescence line of ruby relative to the room-pressure reading before and after each experiment. The wavelength shift was converted to pressures using the calibration of Mao et al. (1986), and the precision of the pressure measurements is estimated to be better than $\pm 0.03 \mathrm{GPa}$.

An automated Picker four-circle diffractometer operating with filtered $\mathrm{MoK} \alpha$ radiation $(\lambda=0.7107 \AA)$ was
TABle 2. Results from structure refinements of magnesite at high pressure

\begin{tabular}{cccccc}
\hline \hline$P(\mathrm{GPa})$ & $N_{\text {TOT }}$ & $\begin{array}{c}N_{\text {OSS }} \\
\left(>3 \sigma_{j}\right)\end{array}$ & $R$ & $R_{\mathrm{w}}$ & $G_{\text {ff }}{ }^{*}$ \\
\hline 0.001 & 56 & 49 & 0.035 & 0.039 & 1.77 \\
2.26 & 55 & 41 & 0.028 & 0.033 & 1.73 \\
3.09 & 69 & 58 & 0.026 & 0.023 & 1.26 \\
4.16 & 59 & 54 & 0.039 & 0.042 & 2.43 \\
4.77 & 56 & 48 & 0.036 & 0.038 & 2.33 \\
6.05 & 55 & 41 & 0.028 & 0.030 & 1.59 \\
\hline
\end{tabular}

Note: $R=\Sigma\left\|F_{\mathrm{o}}|-| F_{\mathrm{c}}\right\| / \Sigma\left|F_{\mathrm{o}}\right| ; R_{\mathrm{w}}=\left[\Sigma \mathrm{w}\left(\left|F_{\mathrm{o}}\right|-\left|F_{\mathrm{c}}\right|^{2 / 2}\left|F_{\mathrm{o}}\right|^{1 / 2}\right.\right.$

* $G_{f t 1}=$ Estimated standard deviation of unit-weight observation.

used throughout the experiment. Unit-cell parameters were obtained at each pressure from a vector leastsquares fit (Ralph and Finger 1982) to the positions of $16-20$ reflections in the range $20^{\circ}<2 \theta<30^{\circ}$ centered at eight equivalent positions following the procedure of King and Finger (1979). Initial unit-cell refinements were made without constraints (i.e., as triclinic) to test for deviations from hexagonal dimensionality. At all pressures $a$ and $b$ were within two estimated standard deviations (esd) of each other, $\alpha$ and $\beta$ were within two esd of $90^{\circ}$, and $\gamma$ was within two esd of $120^{\circ}$. Final cell parameters were calculated with hexagonal constraints (Ralph and Finger 1982) and are reported in Table 1.

Full sets of intensity data for magnesite were collected at $0.0,2.26,3.09,4.16,4.77$, and $6.05 \mathrm{GPa}$. All accessible reflections, including crystallographically equivalent reflections, to $(\sin \theta) / \lambda \leq 0.7$ were obtained using $\omega$ scans with $0.025^{\circ}$ steps and 4.0 second-per-step counting times. Standard reflections were collected every $180 \mathrm{~min}$, and no significant change was observed in these reflections during the course of any data collection. Corrections to $I$ were made for Lorentz and polarization effects and absorption by the components of the diamond-anvil cell. Absorption corrections for the crystal were made with program ABSORB (Burnham 1966), yielding minimum and maximum transmission factors of 97 and $99 \%$. A reflection was considered unobserved when $I \leq 3 \sigma_{l}$. Absorption-corrected data were symmetry-averaged in Laue group $3 m$ prior to each refinement resulting in approximately 60 independent observations at each pressure.

Refinements were carried out with the least-squares program RFINE90, a development version of RFINE4 program (Finger and Prince 1975). A weight of $\sigma^{-2}\left(F_{\mathrm{o}}\right)$ was assigned to each reflection, where $\sigma\left(F_{0}\right)$ is the error derived from counting statistics, and the function minimized was $\Sigma w\left(\left|F_{\mathrm{o}}\right|-\left|F_{\mathrm{c}}\right|\right)^{2}$. The refinements were initiated with the atomic coordinates of Effenberger et al. (1981), and atomic scattering curves for neutral atoms and corrections for anomalous dispersion were taken from the International Tables for X-ray Crystallography (Ibers and Hamilton 1974). Results of the refinements are recorded in Table 2, and the refined positional and thermal parameters are presented in Table 3. Observed and cal- 
TABLE 3. Refined positional coordinates and isotropic displacement factors, $B\left(\AA^{2}\right)$, of magnesite at elevated pressures

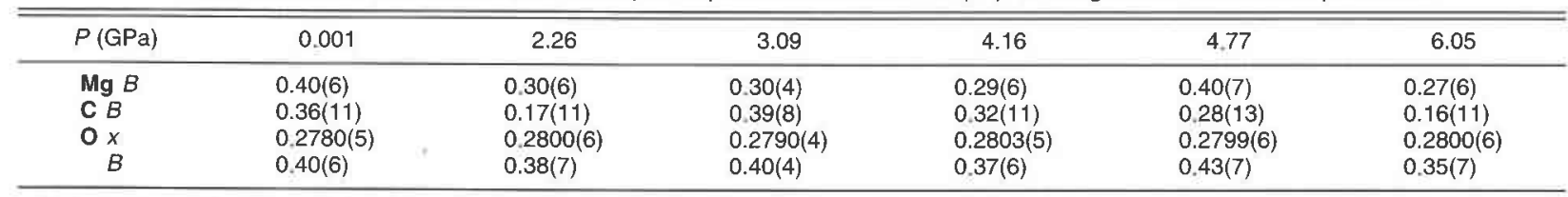

Notes: $\mathrm{Mg}$ occupies site $6(b)$ with $x=y=z=0 ; \mathrm{C}$ occupies site $6(a)$ with $x=0, y=0$, and $z=0.25$, and $\mathrm{O}$ occupies site $18(e)$ with $y=0$ and $z=0.25$.

culated structure factors for each high-pressure refinement are listed in Table 4'.

\section{RESUlts}

\section{Unit-cell parameters and equation of state}

The unit-cell parameters measured at room pressure (Table 1) compare well with those reported by previous workers (Effenberger et al. 1981; Reeder 1983; Markgraf and Reeder 1985). The cell parameters show a smooth, continuous decrease with increasing pressure and show no evidence for a phase transition or change in compression behavior. The axial compressibilities, $a / a_{0}$ and $c / c_{0}$, are plotted as a function of pressure in Figure 1. The mean (linear) compressibilities of the $a$ and $c$ axes are $1.88(2) \times 10^{-3} \mathrm{GPa}^{-1}$ and $4.22(3) \times 10^{-3} \mathrm{GPa}^{-1}$, respectively. Thus, the $c$ axis is approximately twice as compressible as the $a$ axis, so that the axial ratio, cla, decreases with pressure from 3.241 at room pressure to 3.188 at $6.88 \mathrm{GPa}$.

The variation of $V / N_{0}$ with pressure is also shown in Figure 1. Equation of state (EOS) parameters of magnesite were determined by a least-squares fit of a third-order Birch-Murnaghan EOS to the $19 P-V$ data between 0 and $7 \mathrm{GPa}$, refining the volume at room pressure, $V_{0}$, roompressure bulk modulus, $K_{T,}$ and pressure-derivative of the bulk modulus, $K_{T}^{\prime}$. The equation of state of magnesite determined from this analysis has parameters $V_{0}=$ 279.41(8) $\AA^{3}, K_{T}=117(3) \mathrm{GPa}$, and $K_{T}^{\prime}=2.3(7)$, and, if $K_{T}^{\prime}$ is constrained to 4 (i.e., second-order Birch-Murnaghan equation of state), the refined value of $K_{T}$ is $111(1)$ GPa.

\section{Structural changes with pressure}

Magnesite is isostructural with calcite and consists of layers of $\mathrm{Mg}$ atoms that alternate with layers of $\mathrm{CO}_{3}$ groups with the $\mathrm{O}$ atoms roughly approximating a pattern of hexagonal close packing. The $\mathrm{C}$ atom lies in the plane defined by its three neighboring $\mathrm{O}$ atoms that is parallel to the $a-b$ plane. $\mathrm{Mg}$ cations are octahedrally coordinated to six $\mathrm{O}$ atoms, which, in turn, are collectively bonded to six different $\mathrm{Mg}$ atoms and six different $\mathrm{C}$ atoms. Thus the structure can be described in terms of polyhedral link-

\footnotetext{
${ }^{1}$ For a copy of Table 4, order Document AM-97-642 from the Business Office, Mineralogical Society of America, 1015 Eighteenth Street NW, Suite 601, Washington, DC 20036, U.S.A Please remit $\$ 5.00$ in advance for the microfiche. Deposit items may also be available on the American Mineralogist web site, refer to inside back cover of a current issue for web address.
}

ages as consisting of corner-sharing octahedra and trigonal carbonate units.

The $\mathrm{CO}_{3}$ groups are incompressible, rigid units. As shown in Figure $2 b$, the $\mathrm{C}-\mathrm{O}$ distance does not vary by more than two esd between room pressure and $7 \mathrm{GPa}$. Unlike the carbonate groups, the $\mathrm{MO}_{6}$ octahedra show significant compression (Fig. 2a). The (linear) compressibility of $\mathrm{Mg}-\mathrm{O}$ bonds in magnesite, for example, is 3.0 $\times 10^{-3} \mathrm{GPa}^{-1}$, and the polyhedral bulk modulus of $\mathrm{MgO}_{6}$ calculated from a linear regression of the pressure-octahedral volume data (Table 5) is $113 \mathrm{GPa}$.

At room pressure and temperature, the $\mathrm{MgO}_{6}$ octahedra are trigonally distorted by elongation along the threefold axis as reflected in the quadratic elongation (QE) values (Robinson et al. 1971) given in Table 5. The values determined in this study at room pressure are in excellent agreement with the values from previous studies (Effenberger et al. 1981; Reeder 1983; Markgraf and Reeder

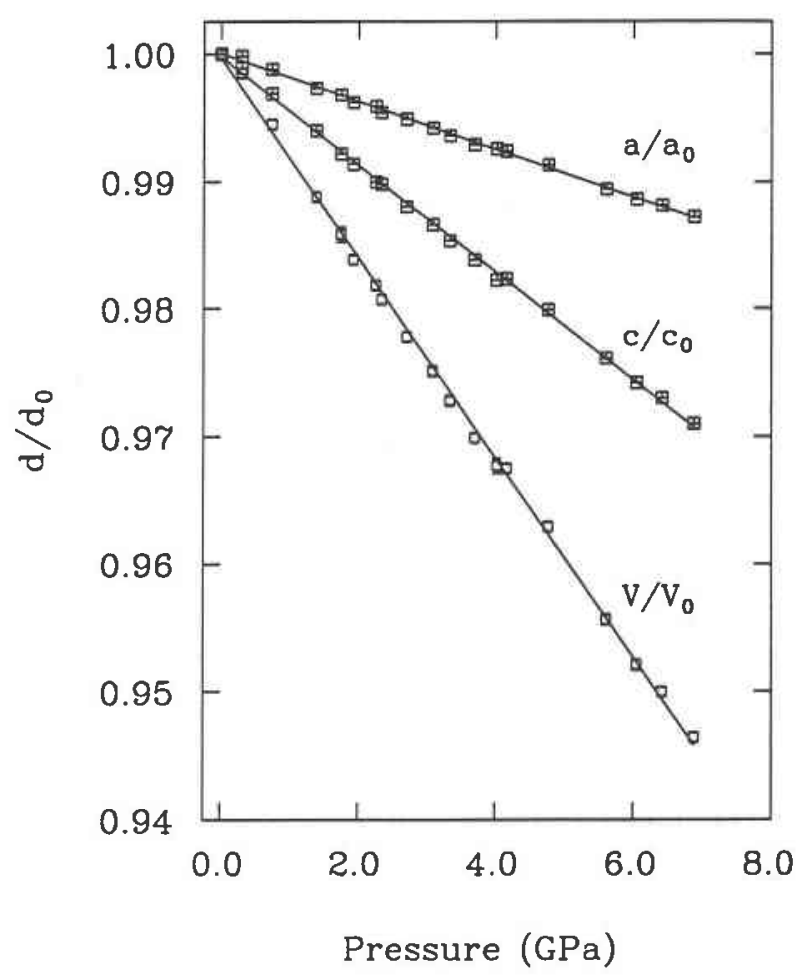

Figure 1. The variation of $a / a_{0}, c / c_{0}$, and $V / V_{0}$ of magnesite as a function of pressure with linear regressions of the data shown. 

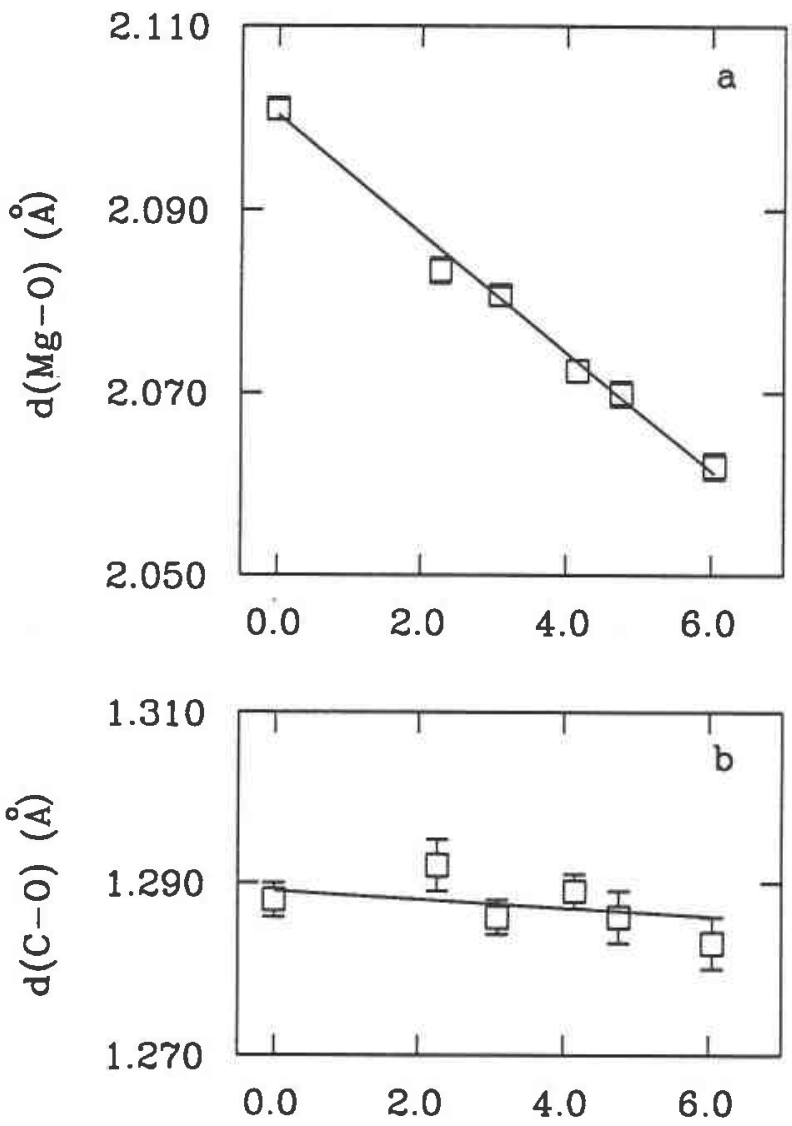

Pressure (GPa)

Figure 2. Variation of (a) $\mathrm{Mg}-\mathrm{O}$ bond lengths and (b) $\mathrm{C}-\mathrm{O}$ bond lengths with pressure in magnesite.

1985). It should be noted that the absolute values of the distortions are very small and the cation octahedra are nearly regular. With increasing pressure, there is a suggestion that the distortion of the $\mathrm{MgO}_{6}$ octahedron decreases slightly as the $\mathrm{QE}$ decreases from 1.0010 at room pressure to 1.0006 at $6.05 \mathrm{GPa}$. The changes in $\mathrm{O}-\mathrm{Mg}-\mathrm{O}$ angles (Table 5) show a trend of decreasing trigonal dis- tortion with increasing pressure more clearly, with the angle variance decreasing from 3.72 at room pressure to 2.14 at $6.05 \mathrm{GPa}$.

The basis for these trends in polyhedral distortion is due to the difference in the compressibilities of the $\mathrm{O}-\mathrm{O}$ interatomic distances within the octahedra. It is apparent from Table 5 that the basal edge (O1-O2 distance) is significantly shorter than the lateral edge (O1-O6). For the $\mathrm{MgO}_{6}$ octahedron in magnesite, the (linear) compressibilities of the lateral edge and basal edge are $3.65 \times 10^{-3}$ $\mathrm{GPa}^{-1}$ and $2.39 \times 10^{-3} \mathrm{GPa}^{-1}$, respectively. Thus the lateral edge length is approximately 1.5 times more compressible than the basal edge length. The decrease in the basal edges of the $\mathrm{MgO}_{6}$ octahedra with pressure control, for the most part, the compression of the $a$ axis because the $\mathrm{CO}_{3}$ groups, which lie parallel to the $a-b$ plane, are essentially incompressible units. The compression between these $\mathrm{O}$ layers, controlled in part by compression of the lateral edges of the $\mathrm{MgO}_{6}$. however, is much great$\mathrm{er}$, and is reflected in the greater compressibility of $c$ relative to $a$.

\section{Discussion}

The anisotropic compression of the cell parameters of magnesite is similar to that observed in other rhombohedral carbonates. As shown above, the $c$ axis is approximately 2.2 times as compressible at the $a$ axis, which is in good agreement with the Zhang et al. (1996) study in which they observed that $c$ is approximately 2.1 times as compressible as $a$, and the Fiquet et al. (1994) high-pressure study in which they observed that $c$ is approximately 2.5 times as compressible as $a$. Redfern et al. (1993) found that the $c$ axis of magnesite is approximately three times as compressible as the $a$ axis. The absolute values of $\beta_{a}$ and $\beta_{c}$ differ between these studies, and this may be due, in part, to the presence of nonhydrostatic stress in the diamond-anvil cells, as discussed below. In Ca-bearing rhombohedral carbonates, dolomite and ankerite, $c$ is approximately three times as compressible as $a$ (Ross and Reeder 1992; Martinez et al. 1996). The compressibility of $c$ in these phases is approximately 1.5 times greater than the compressibility of $c$ in magnesite, where-

TABLE 5. Interatomic distances $(\AA)$ and angles $\left(^{\circ}\right)$ for magnesite between 0 and $6.1 \mathrm{GPa}$

\begin{tabular}{|c|c|c|c|c|c|c|}
\hline$P(\mathrm{GPa})$ & 0.001 & 2.26 & 3.09 & 4.16 & 4.77 & 6.05 \\
\hline \multicolumn{7}{|c|}{$\mathrm{Mg}$} \\
\hline $\mathrm{Mg}-\mathrm{O}$ & $2.1010(10)$ & $2.0834(14)$ & $2.0807(9)$ & $2.0724(12)$ & $2.0699(14)$ & $2.0619(14)$ \\
\hline $01-06$ & $3.0188(8)$ & $2.9909(9)$ & $2.9838(6)$ & $2.9713(8)$ & $2.9658(10)$ & $2.9514(10)$ \\
\hline $01-02$ & $2.923(2)$ & $2.901(3)$ & $2.901(2)$ & $2.890(3)$ & $2.888(3)$ & $2.880(3)$ \\
\hline 01-Mg-O6 & $91.85(3)$ & $91.74(4)$ & $91.62(2)$ & $91.60(3)$ & $91.52(4)$ & $91.40(4)$ \\
\hline $\mathrm{MgO}_{6}$ vol. & 12.346 & 12.041 & $\begin{array}{l}11.997 \\
\text { (1) }\end{array}$ & 11.853 & 11.812 & 11.677 \\
\hline Ang. var. ${ }^{*}$ & 3.720 & 3.317 & 2.857 & 2.783 & 2.516 & 2.143 \\
\hline $\mathrm{QE}^{*}$ & 1.0010 & 1.0009 & 1.0008 & 1.0008 & 1,0007 & 1.0006 \\
\hline \multicolumn{7}{|c|}{ c } \\
\hline $\mathrm{C}-\mathrm{O}$ & $1.288(2)$ & $1.292(3)$ & $1.286(2)$ & $1.289(2)$ & $1.286(3)$ & $1.283(3)$ \\
\hline $0-0$ & $2.231(4)$ & $2.238(5)$ & $2.227(3)$ & $2.233(4)$ & $2.227(5)$ & $2.222(5)$ \\
\hline
\end{tabular}


as the compressibility of $a$ is comparable in magnitude. Thus the axial ratio, $c / a$, decreases more rapidly with pressure in Ca-bearing rhombohedral carbonates.

Similar to other rhombohedral carbonates, the dominant response of the structure of magnesite to pressure is compression of the $\mathrm{MO}_{6}$ octahedra. The carbonate groups behave as rigid, incompressible units. Unlike calcite that undergoes two phase transitions between 0 and $3 \mathrm{GPa}$ at room temperature (Merrill and Bassett 1975), no phase transition has been observed in any $\mathrm{Mg}$-bearing rhombohedral carbonate at high pressure and room temperature under hydrostatic conditions. It is therefore of interest to compare the polyhedral bulk moduli $\left(K_{\mathrm{P}}\right)$ in rhombohedral carbonates. Ross and Reeder (1992) found that $\mathrm{MgO}_{6}$ in dolomite is more compressible than would be expected from high-pressure structural studies of $\mathrm{Mg}$-bearing oxides and silicates (e.g., Hazen and Finger 1982). They found, in fact, that the polyhedral bulk modulus of $\mathrm{MgO}_{6}$ in dolomite $(98 \mathrm{GPa})$ shows the greatest difference with $K_{\mathrm{P}}$ of $\mathrm{MgO}_{6}$ in periclase (161 GPa). Redfern et al. (1993) suggested that $K_{\mathrm{P}}$ of $\mathrm{MgO}_{6}$ in magnesite should be higher than that of dolomite and closer to the values measured in periclase and monticellite $\left(K_{\mathrm{P}}=150 \mathrm{GPa}\right.$; Sharp et al. 1987). In this study, the polyhedral bulk modulus of $\mathrm{MgO}_{6}, 113 \mathrm{GPa}$, although greater than that observed in dolomite, is approximately $30 \%$ lower than that of $\mathrm{MgO}$. As Ross and Reeder (1992) suggested, metal-metal interactions may play a more significant role in $\mathrm{NaCl}$ structures than in the structures of rhombohedral carbonates, resulting in less compressible octahedra.

The above findings are consistent with the systematic study of Martens et al. (1982) of the compressibility of carbonates with the calcite and aragonite structures. They found that the bulk compressibilities of carbonates $\left(\beta_{\mathrm{MCO}_{3}}\right)$ are related to their mean $\mathrm{M}-\mathrm{O}$ bond length $(d\langle\mathrm{M}-$ O) ) by the linear relationship,

$$
\beta_{\mathrm{MCO}_{3}}\left(\mathrm{GPa}^{-1}\right)=0.00097(d\langle\mathrm{M}-\mathrm{O}\rangle)^{3}\left(\AA^{3}\right)
$$

which is approximately $60 \%$ greater than the compressibilities of the corresponding oxide polyhedra as determined by Hazen and Prewitt (1977). Moreover, the compressibility of magnesite $\left(\beta=K^{-1}\right)$ determined in this study, $8.6 \times 10^{-3} \mathrm{GPa}^{-1}$ (or $9.0 \times 10^{-3} \mathrm{GPa}^{-1}$ if $K_{T}^{\prime}=4$ ), is in good agreement with $\beta_{\mathrm{MgCO}_{3}}$ predicted by the above equation, $9.0 \times 10^{-3} \mathrm{GPa}^{-1}$, as is the Zhang et al. (1996) value of $9.3 \times 10^{-3} \mathrm{GPa}^{-1}$ (or $9.7 \times 10^{-3} \mathrm{GPa}^{-1}$ if $K_{T}^{\prime}=$ 4). However, the compressibilities determined by Redfern et al. (1993), $6.6 \times 10^{-3} \mathrm{GPa}^{-1}$ (or $7.0 \times 10^{-3} \mathrm{GPa}^{-1}$ if $K_{T}^{\prime}=4$ ), and Fiquet et al. (1994), $6.4 \times 10^{-3} \mathrm{GPa}^{-1}$ (or $7.2 \times 10^{-3} \mathrm{GPa}^{-1}$ if $K_{T}^{\prime}=4$ ), are both approximately $25 \%$ lower than that predicted by the above equation.

The EOS parameters of magnesite determined from these different studies are summarized in Table 6. Although $K_{T}$ determined in this study is approximately $20 \%$ lower than $K_{T}$ reported by Redfern et al. (1993) and Fiquet et al. (1994), it is in very good agreement with $K_{T}$ determined by Zhang et al. (1996) and the acoustic measurements of Humbert and Plicque (1972) and Christen-
TABLE 6. Equation of state parameters of magnesite

\begin{tabular}{lcll}
\hline \hline \multicolumn{1}{c}{ Method } & $K_{0}(\mathrm{GPa})$ & $K_{0}^{\prime}$ & \multicolumn{1}{c}{ Reference } \\
\hline Acoustic & 112 & - & Christensen (1972) \\
& & & \\
Acoustic & 113.8 & - & Humbert and Plicque (1972) \\
X-ray: powder & $142(9)$ & 4 & Redfern et al. (1993) \\
& $151(7)$ & 2.5 & \\
X-ray: powder & $138(3)$ & 4 & Fiquet et al. (1994) \\
& $156(4)$ & $2.5(2)$ & \\
X-ray: powder & $103(1)$ & 4 & Zhang et al. (1996) \\
X-ray: single crystal & $108(3)$ & 2.3 & This work \\
& $111(1)$ & 4 & \\
\hline & $117(3)$ & $2.3(7)$ & \\
\hline
\end{tabular}

sen (1972). Recently, Reynard et al. (1996) investigated the effect of nonhydrostatic pressure media on determinations of pressure in the diamond-anvil cell and found that pressures were systematically overestimated using the ruby fluorescence technique when their pressure medium became nonhydrostatic. They attributed this to the effect of nonhydrostatic stress on the position of the ruby fluorescence peak. Reynard et al. (1996) further speculated that this may have been the cause of the discrepancy in the EOS of dolomite determined by Fiquet et al. (1994) and Ross and Reeder (1992). In the high-pressure experiments of Fiquet et al. (1994), silicone oil was used as a pressure-transmitting medium. Silicone oil may be quasihydrostatic at low pressures, but it will certainly become nonhydrostatic at the high pressures of their study (53 GPa). In this study and the previous high-pressure study of dolomite and ankerite (Ross and Reeder 1992), a 4:1 nondried mixture of methanol:ethanol was used as the pressure-transmitting medium, which is hydrostatic over the pressure ranges studied. The higher bulk moduli obtained by Fiquet et al. (1994) for both dolomite and magnesite are consistent with an overestimation of pressure based on the position of the ruby fluorescence peak. Nonhydrostatic stress may also be the cause of the anomalous compression behavior of magnesite observed by Fiquet et al. (1994) near $25 \mathrm{GPa}$. In contrast, the technique used by Zhang et al. (1996) involved using $P-V-T$ data collected above $873 \mathrm{~K}$ on heating and in the entire cooling cycle to minimize the effect of nonhydrostatic stress. The good agreement between EOS parameters determined in this study with the Zhang et al. (1996) study suggest that this technique is effective in annealing out deviatoric stress.

Similar to this study, Redfern et al. (1993) used a 4:1 methanol:ethanol mixture as the pressure-transmitting medium, and pressures were determined from the EOS of $\mathrm{NaCl}$ included as a calibrant in their DAC. The 4:1 methanol:ethanol mixture remains hydrostatic to almost 10 $\mathrm{GPa}$ at room temperature (Piermarini et al. 1973). In Figure 3 , the volume compression data from this study are compared with data of Redfern et al. (1993) to $10 \mathrm{GPa}$. Figure 3 shows that the studies are in good agreement ( \pm 1 esd) below $6 \mathrm{GPa}$ and in reasonable agreement $( \pm 2$ esd) between 5 and $7 \mathrm{GPa}$. Above $7 \mathrm{GPa}$, the discrepancy 


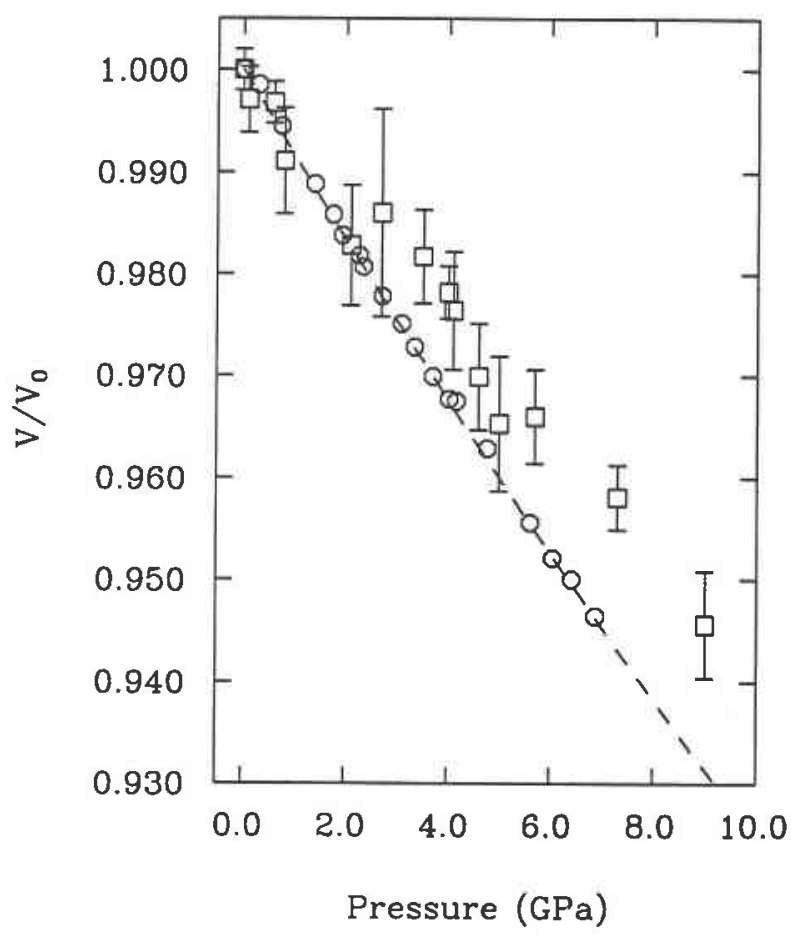

Figure 3. Comparison of compression data of this study (circles) with the Redfern et al. (1993) data (squares) below 10 $\mathrm{GPa}$. The error bars shown are \pm 1 esd (the sizes of the circles are also \pm 1 esd).

between the two studies increases. This may be due to the pressure medium becoming more nonhydrostatic caused, perhaps, by loading a large amount of powdered sample in the diamond-anvil cell relative to the pressuretransmitting medium. While it is still not definite why results from this study differ with the Redfern et al. (1993) results, the discrepancy with the Fiquet et al. (1994) study clearly shows that the presence of nonhydrostatic stress may lead to erroneous determinations of the EOS of a phase. This will be more critical for minerals such as carbonates that have large compressibilities.

\section{ACKNOWLEDGMents}

The magnesite specimen was kindly provided by G. Cressey of the British Museum of Natural History (BMNH). X-ray diffractometry facilities at UCL were established with funds from the Court of the University of London, the Royal Society, and the UGC, and are maintained through grant GR3/9782 from the Natural Environment Research Council of Great Britain.

\section{REFERENCES CITED}

Angel, R.J., Ross, N.L., Wood, I.G., and Woods, P.A. (1992) Single-crystal $\mathrm{X}$-ray diffraction of high pressures with diamond-anvil cells. Phase Transitions, 39, 13-32.

Berg, G.W. (1986) Evidence for carbonate in the mantle Nature, 324, 50 51.

Biellmann, C., Gillet, P., Guyot, F., Peyronneau, J., and Reynard, B. (1993) Experimental evidence for carbonate stability in the Earth's lower mantle. Earth and Planetary Science Letters, 118, 31-41.

Brey, G., Brice, W.R., Ellis, D.J., Green, D.H., Harris, K.L., and Ryabchi- kov, I.D. (1983) Pyroxene-carbonate reactions in the upper mantle. Earth and Planetary Science Letters, 62, 64-74.

Burnham, C.W. (1966) Computation of absorption corrections and the significance of end effects. American Mineralogist, 51, 159-167.

Canil, D. and Scarfe, C.M. (1990) Phase relations in peridotite $+\mathrm{CO}_{2}$ systems at $12 \mathrm{GPa}$ : Implications for origin of kimberlite and carbonate stability in the Earth's upper mantle. Journal of Geophysical Research, $95,15805-15816$.

Christensen, N.I. (1972) Elastic properties of polycrystalline magnesium, iron, and manganese carbonates to 10 kilobars. Journal of Geophysical Research, 77, 369-372.

Effenberger, H., Mereiter, K., and Zemann, J. (1981) Crystal structure refinements of magnesite, calcite, rhodochrosite, siderite, smithsonite, and dolomite, with discussion of some aspects of the stereochemistry of calcite-type carbonates. Zeitschrift für Kristallographie, 156, 233243.

Finger, L.W. and Prince, E. (1975) A system of Fortran IV computer programs for crystal structure computations. U.S. National Bureau of Standards Technical Note 854, Washington D.C., $129 \mathrm{p}$.

Fiquet, G., Guyot, F., and Itié, J.P. (1994) High-pressure X-ray diffraction study of carbonates: $\mathrm{MgCO}_{3}, \mathrm{CaMg}\left(\mathrm{CO}_{3}\right)_{2}$, and $\mathrm{CaCO}_{3}$. American Mineralogist, $79,15-23$.

Gillet, P. (1993) Stability of magnesite $\left(\mathrm{MgCO}_{3}\right)$ at mantle pressure and temperature conditions: A Raman spectroscopic study. American Mineralogist, 78, 1328-1331.

Hazen R.M. and Finger, L.W. (1982) Comparative Crystal Chemistry. Wiley, New York, $231 \mathrm{p}$.

Hazen, R.M. and Prewitt, C.T. (1977) Effects of temperature and pressure on interatomic distances in oxygen-based minerals. American Mineralogist, 62, 309-315.

Humbert, P. and Plicque, F. (1972) Propriétés élastiques de carbonates rhombohédriques monocristallins: Calcite, magnésite, dolomite. Comptes Rendus de l'Académie des Sciences de Paris, 275, 391-394.

Ibers, J.A. and Hamilton, W.C., Eds. (1974) International tables for X-ray Crystallography, vol. IV, 366 p. Kynoch, Birmingham, U.K

Katsura, T. and Ito, E. (1990) Melting and subsolidus phase relations in the $\mathrm{MgSiO}_{3} \cdot \mathrm{MgCO}_{3}$ system at high pressures: Implications to evolution of the Earth's atmosphere. Earth and Planetary Science Letters, 99, 110117.

Katsura, T., Tsuchida, Y., Ito, E., Yagi, T., Utsumi, W., and Akimoto, S. (1991) Stability of magnesite under lower mantle conditions. Proceedings of the Japanese Academy, 67, 57-60.

King, H.E. and Finger, L.W. (1979) Diffracted beam crystal centering and its application to high-pressure crystallography. Journal of Applied Crystallography, 12, 374-378.

Kushiro, I., Satake, H., and Akimoto, S. (1975) Carbonate-silicate reactions at high pressures and possible presence of dolomite and magnesite in the upper mantle. Earth and Planetary Science Letters, 18, 408-410.

Mao, H.K., Xu, J., and Bell, P.M. (1986) Calibration of the ruby pressure gauge to $800 \mathrm{kbar}$ under quasi-hydrostatic conditions. Journal of Geophysical Research, 91, 4673-4676.

Markgraf, S.A and Reeder, R.J. (1985) High-temperature structure refinements of calcite and magnesite. American Mineralogist, 70, 590-600.

Martens, R., Rosenhauer, M., and Gehlen, K. V. (1982) Compressibilities of carbonates. In W. Schreyer, Ed., High-Pressure Researches in Geoscience, p. 215-222. E. Schweizerbart'sche Verlagsbuchhandlung, Stuttgart.

Martinez, I, Zhang, J., and Reeder, R.J. (1996) In situ X-ray diffraction study of aragonite and dolomite at high pressure and temperature: Evidence for dolomite breakdown to aragonite and magnesite. American Mineralogist, 81, 611-624.

McGetchin, T.R. and Besançon, J.R. (1973) Carbonate inclusions in mantle-derived pyropes, Earth and Planetary Science Letters, 18, 408-410.

Merrill, L. and Bassett, W.A. (1975) The crystal structure of $\mathrm{CaCO}_{3}$ (II), a high-pressure metastable phase of calcium carbonate. Acta Crystallographica, B31, 343-349.

Piermarini, G.J., Block, S., and Barnett, J.D. (1973) Hydrostatic limits in liquids and solids to 100 kbar. Journal of Applied Physics, 44, 53775382.

Ralph, R.L. and Finger, L.W. (1982) A computer program for refinement 
of crystal orientation matrix and lattice constants from diffractometer data with lattice symmetry constraints. Journal of Applied Crystallography, 15, 537-539.

Redfern, S.A.T., Wood, B.J., and Henderson, C.M.B. (1993) Static compressibility of magnesite to $20 \mathrm{GPa}$ : Implications for $\mathrm{MgCO}_{3}$ in the lower mantle. Geophysical Research Letters, 20, 2099-2102.

Reeder, R.J. (1983) Crystal chemistry of the rhombohedral carbonates. In Mineralogical Society of America Reviews in Mineralogy, 11, 1-47.

Reynard, B., Fiquet, G., Itié, J.P., and Rubie, D.C. (1996) High-pressure $\mathrm{X}$-ray diffraction study and equation of state of $\mathrm{MgSiO}_{3}$ ilmenite. American Mineralogist, 81, 45-50.

Robinson, K., Gibbs, G.V., and Ribbe, P.H. (1971) Quadratic elongation: A quantitative measure of distortion in coordination polyhedra. Science, 172, 567-570.

Ross, N.L. and Reeder, R.J. (1992) High-pressure structural study of dolomite and ankerite. American Mineralogist, 77, 412-421.
Sharp, Z.D., Hazen, R.M., and Finger, L.W. (1987) High-pressure crystal chemistry of monticellite, $\mathrm{CaMgSiO}_{4}$. American Mineralogist, 72, 748755.

Williams, Q., Collerson, B., and Knittle, E. (1992) Vibrational spectra of magnesite $\left(\mathrm{MgCO}_{3}\right)$ and calcite-III at high pressures. American Mineralogist, 77, 1158-1165.

Wyllie, P.J. and Huang, W.L. (1976) Carbonation and melting reactions in the system $\mathrm{CaO}-\mathrm{MgO}-\mathrm{SiO}_{2}-\mathrm{CO}_{2}$ at mantle pressures with geophysical and petrological implications. Contributions to Mineralogy and Petrology, 54, 79-107.

Zhang, J., Martinez, I., Guyot, F., Gillet, P., and Saxena, S.K. (1996) X-ray diffraction study of magnesite at high pressure and high temperature. Physics and Chemistry of Minerals, 24, 122-130.

MANUSCRIPT RECEIVED SEPTEMBER 23, 1996

Manuscript accepted March 4, 1997 